\title{
Menthol-loaded PLGA Micro and Nanospheres: Synthesis, Characterization and Degradation in Artificial Saliva
}

\author{
Juliana Pelisoli Holz ${ }^{a}$, Marcia Karpinski Bottene ${ }^{c}$, Vanusca Dalosto Jahno ${ }^{c}$, Sandra Einloft ${ }^{\circledR}$, \\ Rosane Ligabue $e^{a, b *}$ \\ a Programa de Graduação em Engenharia e Tecnologia de Materiais, Ponticia Universidade Católica \\ do Rio Grande do Sul (PUCRS), CEP 90619900, Porto Alegre, RS, Brazil \\ ${ }^{b}$ Faculdade de Química, Ponticia Universidade Católica do Rio Grande do Sul (PUCRS), CEP \\ 90619900, Porto Alegre, RS, Brazil \\ 'Instituto de Ciências Exatas e Tecnológicas, Universidade FEEVALE, CEP 93525075, Novo \\ Hamburgo, RS, Brazil
}

Received: May 12, 2017; Revised: October 10, 2017; Accepted: January 07, 2018

\begin{abstract}
Menthol-loaded PLGA micro/nanospheres were synthesized using the multiple emulsion/solvent evaporation technique. Parameters such as stirring rate, external surfactant content, PLGA/menthol weight ratio, solvent evaporation and lyophilization time were evaluated as well as the degradation of micro/nanospheres in an artificial saliva medium. The menthol/PLGA micro/nanospheres thus obtained had a size distribution of between $217 \mathrm{~nm}$ and $13 \mu \mathrm{m}$ and particles with spherical and dense morphology were evidenced by SEM micrographs. FTIR and TGA data showed an increase up to $60 \%$ of menthol incorporated in the micro/nanoparticles. The degradation of menthol-loaded PLGA micro/nanoparticles in artificial saliva significantly affected the particles morphology and appears to be an effective medium for releasing menthol.
\end{abstract}

Keywords: emulsion, menthol, micro/nanospheres, PLGA.

\section{Introduction}

Producing micro/nanoparticles (micro/nanospheres and micro/nanocapsules) that enable controlled and/or sustained release of drugs and active principles is one of nanotechnology's most important research areas. To be effective, these micro/ nanoparticles should have certain characteristics, such as high encapsulation efficiency and keep the drug or active principle preserved during storage. They should also be easily administered to the target site, present a controlled release rate aiming to achieve a therapeutic effect and minimize side effects, as well as increase the intracellular penetration and pharmacological activity $^{1-6}$.

Administering drugs or active principles via microspheres promotes both a protection under adverse conditions as well as a release profile to occur by the desired time ${ }^{5,7}$.

Currently, there is particular interest in preparing micro- and nanospheres using biodegradable polymers, e.g. poly(lactic acid), PLA, and their copolymers, such as poly (lactic acid-co-glycolic acid), PLGA, considering its well-known biocompatibility and biodegradation characteristics $)^{5,8-10}$.

Moreover, these polymers have interesting characteristics and possess a controllable degradation rate that depends on their molecular weight and lactic acid/glycolic acid ratio ${ }^{11}$.
Menthol (cyclic monoterpene alcohol), a potential active principle in micro/nanospheres, is the major constituent of essential oils of plants such as peppermint and spearmint, in addition to having characteristics such as the cooling, minty taste and a characteristic odor. This compound has great commercial significance and is one of the main flavoring substances on the market, with an annual consumption of around 32,000 tonnes ${ }^{12}$. Menthol also has applications in many pharmaceuticals products, cosmetics, sweets, chewing gum, drinks, toothpastes, shampoos, among others, in order to promote freshness and taste. Furthermore, menthol has various biological properties, such as being antimicrobial ${ }^{13}$, anticancer and anti-inflammatory ${ }^{14}$ and its plants can be used as insect repellent ${ }^{12,15}$.

Microspheres or microcapsules can be used to protect the flavoring substances and the active agents from oxidation, which is caused by factors such as heat, light, humidity, or contact with other substances during storage, by preventing evaporation of volatile substances, such as menthol ${ }^{16}$. One method widely employed for preparing micro- and nanoparticles is emulsification followed by evaporation or multiple emulsion, consisting of several steps in which oil/water emulsion formation (o/w) occurs ${ }^{1,4,17-24}$. A drying process can minimize the limited stability of these systems and lyophilization has been widely used for this purpose to dehydrate colloidal systems, especially liposomes and micro or nanospheres ${ }^{22}$. 
There is not study regarding micro- and nanospheres with menthol prepared by multiple emulsion and its behaviour in artificial saliva. Thus, in this context, the main goal of this study was to synthesize and characterize PLGA and menthol microspheres using the multiple emulsion (in this case, double emulsion) technique. Additionally, the degradation of these microspheres in a medium containing artificial saliva was evaluated, aiming to study them in a physiological environment.

\section{Materials and Methods}

\subsection{Materials}

The copolymer PLGA(PLG 8523 - 85:15 L-lactide:glycolide ratio, 99.4\%, PURAC), menthol (99.95\%, Vetec), poly (vinyl alcohol), PVA, (86.5-89.5\%, Vetec) and dichloromethane $\left(\mathrm{CH}_{2} \mathrm{Cl}_{2}, 99.5 \%\right.$, Vetec $)$ were used as receivers. Artificial saliva was prepared according to the standard composition used by patients with dry mouth symptoms (xerostomy) caused by radiotherapy for cancer. The artificial saliva was obtained from a 50/50 v/v mixture of solution A and solution B (Solution A: $0.1662 \% \mathrm{CaCl}_{2}, 0.0558 \% \mathrm{MgCl}_{2}, 0.625 \%$ $\mathrm{KCl}, 0.865 \% \mathrm{NaCl}$ and water purified QSP. Solution B: $0.80 \% \mathrm{~K}_{2} \mathrm{SO}_{4}, 0.32 \% \mathrm{KHSO}_{4}, 1 \%$ sodium benzoate, $50 \%$ sorbitol, $0.04 \%$ sodium fluorate, $0.2 \%$ preservative-methyl/ propyl paraben and water purified QSP).

\subsection{Synthesis of micro/nanospheres of PLGA/Menthol}

Initially the biodegradable copolymer PLGA and the menthol were solubilized in sufficient amounts of $\mathrm{CH}_{2} \mathrm{Cl}_{2}$ (approximately $1 \mathrm{~g}$ polymer $/ 100 \mathrm{~mL} \mathrm{CH}_{2} \mathrm{Cl}_{2}$ ), yielding the oil phase (O). Next, $200 \mathrm{~mL}$ of distilled water as first aqueous phase $\left(A_{1}\right)$ was added to the oil phase $(O)$ by stirring $(3,600$ rpm) with Ultra-turrax ${ }^{\circledR}$ (IKA, model 18 basic), thus producing the primary emulsion $\left(\mathrm{A}_{1} / \mathrm{O}\right)$. This emulsion was added to the $400 \mathrm{~mL}$ of PVA suspension (second aqueous phase, $\mathrm{A}_{2}$ ) by stirring $(24,000$ or $7,000 \mathrm{rpm})$ for 5 minutes, thus yielding a multiple emulsion $\left(\mathrm{A}_{1} / \mathrm{O} / \mathrm{A}_{2}\right)$, forming nanoparticles in suspension. Next, the organic solvent was evaporated at room temperature for $12 \mathrm{~h}$ or under reduced pressure with a rotary evaporator $\left(40^{\circ} \mathrm{C}\right.$ for $\left.1 \mathrm{~h}\right)$. Then the micro/nanospheres were isolated by centrifugation ( $5000 \mathrm{rpm}$ equivalent to $1,400 \mathrm{~g}$ ) in $20 \mathrm{~min}$ and washed with distilled water (3 times) to remove the excess PVA. Lastly, the micro/nanoparticles suspensions were frozen with liquid nitrogen and lyophilized (condenser temperature of $-110^{\circ} \mathrm{C}$ to $-100^{\circ} \mathrm{C}$, pump pressure of $0.66 \mathrm{mbar}$ and sample temperature of $-40^{\circ} \mathrm{C}$ ) for the desired time and stored in a desiccator. Nano/microparticles samples with menthol incorporated were submitted the smell essay and it was considered positive (presence of menthol) when the smell was discernible for at least three different individuals.
Table 1 shows the parameters studied (weight ratio for menthol/PLGA, PVA content in the water phase $\left(\mathrm{A}_{2}\right)$, stirring rate, time of solvent evaporation and lyophilization) in the preparation of the PLGA/menthol micro/nanospheres and PLGA particles (without menthol).

\subsection{Preparing the samples for degradation in artificial saliva}

Degradation tests in artificial saliva were carried out with the NP-3 and NP-5 samples (Table 1). These samples (five samples of each) were weighed on an analytical balance (accuracy of $\pm 0.0001 \mathrm{~g}$, Bel Engineering Ltda). Next, the samples were placed in Falcon tubes containing $10 \mathrm{~mL}$ of artificial saliva $(\mathrm{pH}=7)$ at $37^{\circ} \mathrm{C}$ and removed at determined times (7, 14, 30, 60 and 90 days). The samples removed from the artificial saliva were centrifuged (500 rpm and 20 minutes) and washed with distilled water (3 times) to remove the excess of saliva solution. Next the samples were dried in an oven (Marconi Ltda) at $100^{\circ} \mathrm{C}$ until a constant weight was achieved and then stored in a desiccator.

\subsection{Characterization of micro/nanoparticles}

\subsubsection{Fourier transform infrared spectroscopy (FTIR)}

The chemical structures of the PLGA/menthol micro/ nanoparticles were characterized by FTIR (PerkinElmer Instruments, Spectrum One FTIR Spectrometer or ABB Bomem-MB Series, model Arid-zone). Samples were analyzed in the ATR mode in the $4000-650 \mathrm{~cm}^{-1}$ range, using $\mathrm{SeZn}$ cell or the transmission mode, in the $4000-450 \mathrm{~cm}^{-1}$. The samples were prepared as a film (in THF) or in a $\mathrm{KBr}$ pellet.

\subsubsection{Scanning electron microscopy (SEM)}

The PLGA/menthol micro/nanoparticle morphology was evaluated using the SEM technique (Philips microscope, model XL30 with a resolution of $3.5 \mathrm{~nm}$ in the secondary electron mode), with an accelerating voltage of $20 \mathrm{kV}$ and gold plating samples. After degradation in the artificial saliva, the PLGA/menthol micro/nanoparticles were analyzed using SEM (JEOL microscope, model JSM-6510LV with a resolution of $3.5 \mathrm{~nm}$ in the secondary electron mode), with an accelerating voltage of $5 \mathrm{kV}$ and gold plating samples. The particle size data were obtained using the digital program "Image Tool" (version 2, GPL) that was applied the SEM images. Measurements were taken on average (different images of same sample) from a set of 18 particles to NP-1 and at least 100 particles for others particles.

\subsubsection{Differential scanning calorimetry (DSC)}

Glass transition (Tg), melting (Tm) and crystallization (Tc) temperatures were performed with DSC equipment (TA Instruments, model Q20) in a temperature range of $-90^{\circ} \mathrm{C}$ to $200^{\circ} \mathrm{C}$, with a heating rate of $10^{\circ} \mathrm{C} / \mathrm{min}$, in a nitrogen 
Table 1. Evaluated parameters in preparing micro/nanoparticles using the multiple emulsion technique.

\begin{tabular}{cccccc}
\hline Sample & $\begin{array}{c}\text { Weight ratio } \\
\text { Menthol/PLGA }\end{array}$ & $\begin{array}{c}\text { PVA content } \\
(\% \mathrm{~m} / \mathrm{v})\end{array}$ & Stirring rate (rpm) & $\begin{array}{c}\text { Solvent evaporation } \\
\text { time (h) }\end{array}$ & $\begin{array}{c}\text { Lyophilization } \\
\text { time }(\mathrm{h})\end{array}$ \\
\hline NP-1 & $1: 10$ & 1 & 7,000 & 12 & 24 \\
NP-2 & $1: 5$ & 1 & 24,000 & 12 & 24 \\
NP-3 & $1: 5$ & 1 & 24,000 & $13 *$ & 24 \\
NP-4 & $1: 5$ & 0.5 & 24,000 & 1 & 72 \\
NP-5 & $1: 5$ & 0.5 & 24,000 & 1 & 24 \\
NP-6 & $1: 5$ & 1 & 24,000 & 12 & 24 \\
NP-7 & $1: 5$ & 0.75 & 24,000 & 12 & 24 \\
NP-8 & $1: 5$ & 0.5 & 24,000 & 12 & 24 \\
NP-9 & $1: 2.5$ & 1 & 24,000 & 12 & 24 \\
\hline
\end{tabular}

* Organic solvent was evaporated at room temperature and atmospheric pressure for $12 \mathrm{~h}$ and then under reduced pressure at $40^{\circ} \mathrm{C}$ for $1 \mathrm{~h}$.

atmosphere and using an aluminum sample holder. Analyses were performed in duplicate.

\subsubsection{Thermogravimetric analysis (TGA)}

Thermogravimetric analyses were performed with SDT equipment (TA Instruments, Q600 model), from room temperature up to $1200^{\circ} \mathrm{C}$, at a heating rate of $20^{\circ} \mathrm{C} / \mathrm{min}$, in a nitrogen atmosphere and using a platinum sample holder. Analyses were performed in duplicate.

\section{Results and Discussion}

The PLGA/menthol micro/nanospheres were prepared using different parameters, such as stirring rate, external surfactant content, PLGA/menthol weight ratio, evaporation time for the solvent and lyophilization time. Different conditions were used in preparing the micro/nanoparticles in order to achieve narrow size distribution and regular spherical morphology. The degradation of these micro/ nanospheres in artificial saliva was also analyzed and the results are presented below.

\subsection{Effect of stirring rate}

NP-1 and NP-2 microspheres (Table 1) were prepared with a stirring rate of 7,000 rpm and 24,000 rpm, respectively. As shown in Figure 1b, the NP-2 microspheres have a smooth surface and an average particle size of between $1.12 \mu \mathrm{m}$ and $2.75 \mu \mathrm{m}$ (average particle size of $1.6 \mu \mathrm{m} \pm 0.7 \mu \mathrm{m}$ ). The NP-1 microspheres (Figure 1a) presented an average particle size of between $5.6 \mu \mathrm{m}$ and $13.1 \mu \mathrm{m}$ (average particle size of $9 \mu \mathrm{m} \pm 3 \mu \mathrm{m}$ ), with crowded and irregular structures and some ruptured particles, probably due to the fact of not being fully formed. The higher stirring rate $(24,000 \mathrm{rpm})$ allowed the formation of dense particles with smaller sizes as found by Oliveira ${ }^{21}$. The formation of particles with characteristics of dense matrix is evidenced in Figure 1a, in which it shows some broken particles (poorly formed) where it can observe the inside of the particles indicating that are not hollow particles. Figure 1c shows PLGA microparticles (without menthol, Table 1) used as control particles for comparison with the PLGA/menthol particles obtained. It was obtained aggregated PLGA microspheres with heterogeneity in the particle size (broad particle size distribution) of between $0.7 \mu \mathrm{m}$ and $11.8 \mu \mathrm{m}$ (average particle size of $1.8 \mu \mathrm{m} \pm 1.4 \mu \mathrm{m}$ ).

\subsection{Effect of the evaporation time of the solvent}

In the systems where the organic solvent $\left(\mathrm{CH}_{2} \mathrm{Cl}_{2}\right)$ was removed after only 1 hour, nanospheres without a characteristic smell (NP-4 and NP-5, Table 1) were produced. In the others systems (NP-1 to NP-3 and NP-6 to NP-9), where the $\mathrm{CH}_{2} \mathrm{Cl}_{2}$ was slowly evaporated, microspheres with the odor were produced. It was identified by sensorial analysis of qualitative form.

Figures $2 \mathrm{a}$ and $2 \mathrm{~b}$ show the typical spectra of PLGA/ menthol microspheres (NP-3) in the attenuated total reflectance (ATR) and the transmission techniques, respectively. The presence of characteristic bands of the PLGA polymer at $2955 \mathrm{~cm}^{-1}$ and $2876 \mathrm{~cm}^{-1}$ assigned to $\mathrm{C}-\mathrm{H}$ stretching of the $\mathrm{CH}_{3}$ is highlighted; $1757 \mathrm{~cm}^{-1}$ characteristic of the carbonyl $(\mathrm{C}=\mathrm{O})$ sym ester stretch present in the polymer backbone; $1183 \mathrm{~cm}^{-1}$ assigned to asym stretching of the $\mathrm{C}=\mathrm{O}$ group and at $1090 \mathrm{~cm}^{-1}$ assigned to sym. C-O-C stretch. Typical bands of menthol at $3276 \mathrm{~cm}^{-1}$ assigned to $\mathrm{O}-\mathrm{H}$ group stretching were also observed, as confirmed by the presence of a broad band in figure $2 \mathrm{~b} ; 1044 \mathrm{~cm}^{-1}$ assigned to alicyclic secondary alcohol (6-membered ring); $919 \mathrm{~cm}^{-1}, 876 \mathrm{~cm}^{-1}$ and 769 $\mathrm{cm}^{-1}$ assigned to asym angular deformation in the isopropyl group's plane, as described in the literature ${ }^{8,25,26}$.

The NP-5 nanospheres, obtained by fast solvent evaporation, exhibited a spherical shape and a homogeneous particle size distribution of $217 \mathrm{~nm}$ to $783 \mathrm{~nm}$ (average particle size of $391 \mathrm{~nm} \pm 160 \mathrm{~nm}$ ) (Figure 3a). However, the NP-3 microspheres obtained by slow solvent evaporation had an oval shape and an aggregate particle structure with a particle 


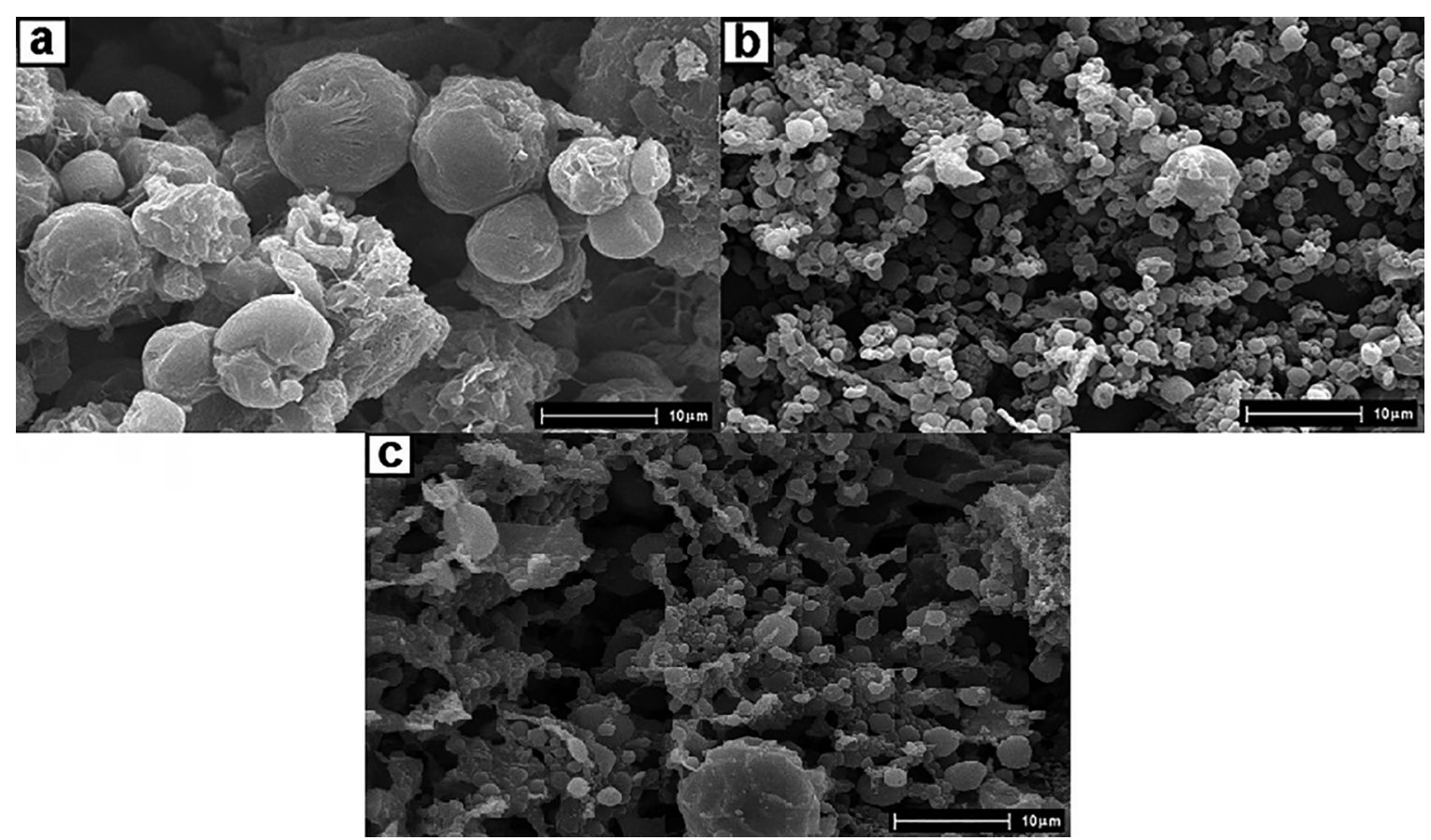

Figure 1. Micrographs of the microparticles: (a) NP-1, (b) NP-2 and (c) PLGA particles (4000x magnification)

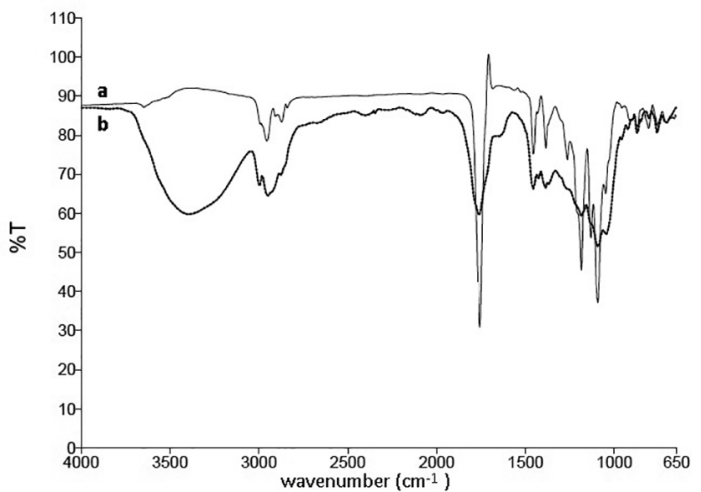

Figure 2. FTIR spectra of the NP-3 microspheres obtained by (a) ATR and (b) transmission techniques

size distribution of $1.9 \mu \mathrm{m}$ to $5.8 \mu \mathrm{m}$ (average particle size of $3 \mu \mathrm{m} \pm 1 \mu \mathrm{m}$ ) (Figure $3 \mathrm{~b}$ ). Comparing the NP-3 with the NP-2 microspheres (same the amount of PVA), this last have an smaller average particle size of between $1.12 \mu \mathrm{m}$ and $2.75 \mu \mathrm{m}$ (average particle size of $1.6 \mu \mathrm{m} \pm 0.4 \mu \mathrm{m}$ ) indicating the real effect solvent evaporation process.

Polymer nanoparticles are often defined as particles with dimensions of between 10nm and $1000 \mathrm{~nm}$, including nanospheres and nanocapsules (Feczkó et al., 2011). In this work, micro- and nanospheres with dense matrix structures were prepared, wherein the menthol molecules can be adsorbed on the surface or incorporated into the polymer matrix. The literature shows that nanoparticles with a nonspherical shape can also be produced ${ }^{27,28}$. Abdelwahed et al. prepared poly(caprolactone) nanospheres with an oval shape and they attributed this peculiar morphology to the surfactant (PVA) used ${ }^{29}$.

\subsection{Effect of lyophilization time}

NP-4 Nanoparticles were obtained under the same conditions as the NP-5 except for the lyophilization time ( $72 \mathrm{~h}$ for the NP-4 and $24 \mathrm{~h}$ for the NP-5, Table 1 ). It could be seen that a longer lyophilization time led to the formation of nanospheres with heterogeneous sizes and in clusters like beads on a chain (Figure 4a) or similar to loose spheres (Figure 4b). Figure 5 shows the NP-5 nanospheres obtained after $24 \mathrm{~h}$ of lyophilization (Table 1). These spheres had a more homogenous distribution and smaller particle size (average particle size of $391 \mathrm{~nm} \pm 160 \mathrm{~nm}$ ) when compared to NP-4 (average particle size of $1.0 \mu \mathrm{m} \pm 0.6 \mu \mathrm{m}$ ). This behavior can be explained by effect of lyophilization time, where longer times can lead the morphology modification and increase of solute nucleation ${ }^{22,30}$.

Process parameters influence of different form the particle size distribution. A larger stirring rate in the emulsion step led to smaller particle sizes in micrometer scale. For the other side a lesser solvent evaporation time and of lyophilization resulted in nanometric particles. This behavior was also described in the literature ${ }^{17,22}$.

\subsection{Effect of PVA content and menthol/PLGA ratio}

The increase in the menthol/PLGA ratio from 1:2.5 to 1:5 (NP-9 and NP-6, respectively) resulted in the increase of intensity of the menthol bands as highlighted 


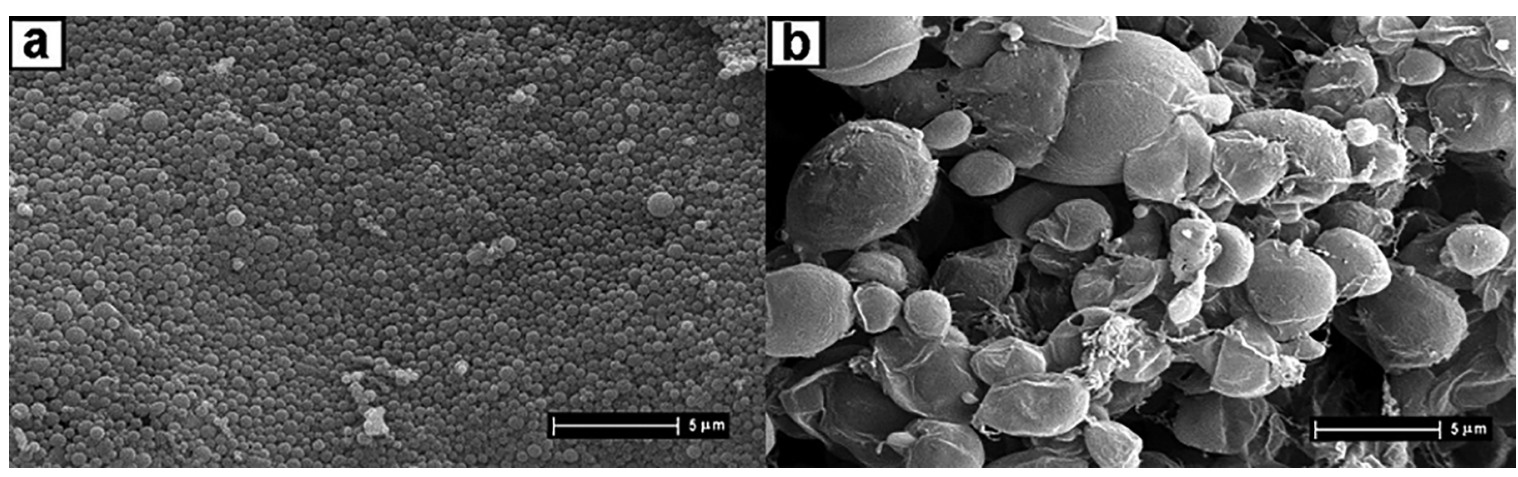

Figure 3. Micrographs of nano/microspheres: (a) NP-5 and (b) NP-3 (8000x magnification)

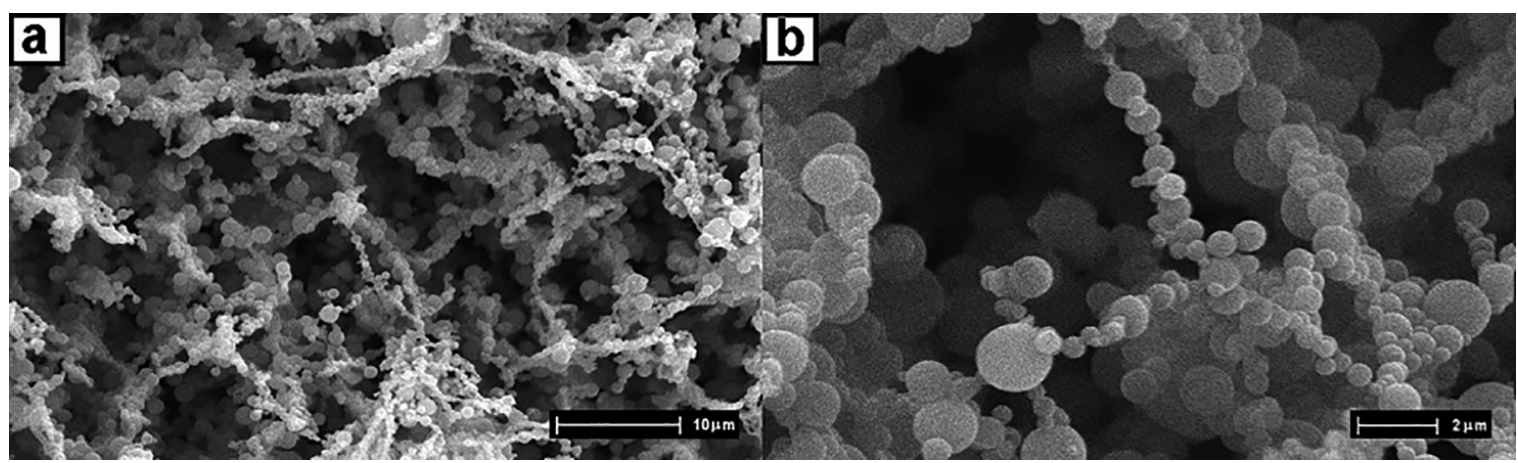

Figure 4. Micrographs of NP-4 microspheres: (a) 4000x and (b) 16000x

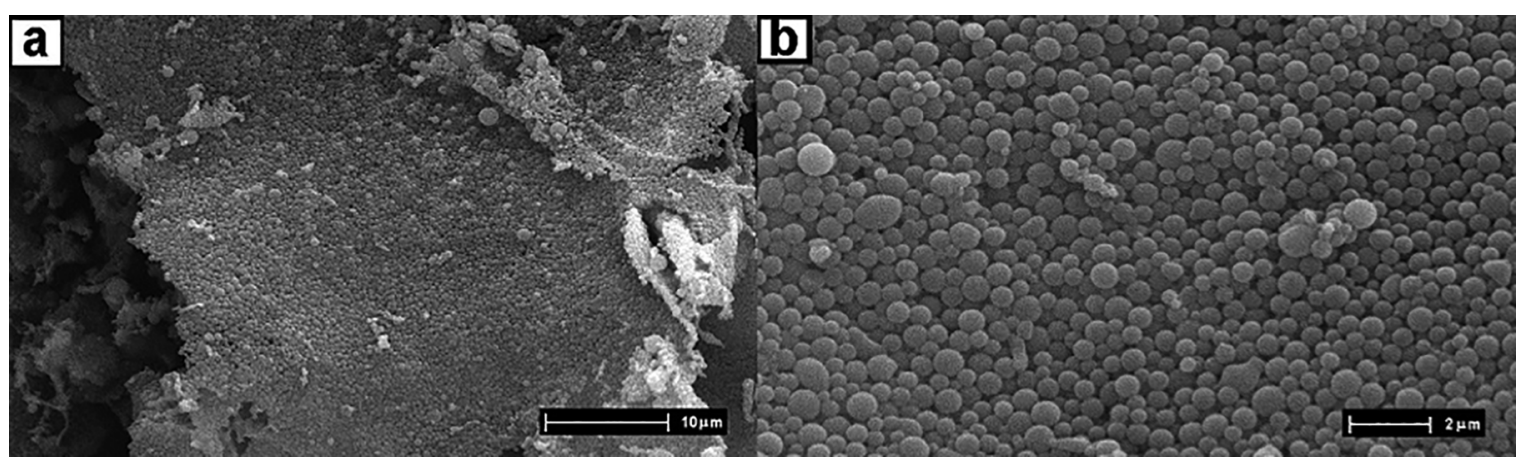

Figure 5. Micrographs of NP-5 nanospheres: (a) 4000x and (b) 16000x

in Figure 6. Comparing the relative heights of the bands at $1044 \mathrm{~cm}^{-1}$ (menthol) and $1754 \mathrm{~cm}^{-1}$ (PLGA), one can estimate approximately a $60 \%$ increase in menthol in the NP-9 nanospheres compared to the NP-6 obtained under the same conditions. This result indicates that the double in the menthol/PLGA ratio (1:2.5 in NP-9 compared with 1:5 in NP-6, Table 1) leads an increase in menthol incorporation of approximately $60 \%$. In the same way, a decrease in the PVA content (Table 1) led to an increase in the amount of incorporated menthol in the NP-7 and NP-8, approximately $25 \%$ and $30 \%$ respectively, compared to NP-6.

Figure 6a shows NP-6 microparticles spectrum, what is very similar to PLGA microparticles (without menthol) spectrum (Figure 6c) indicating the presence of a small menthol quantity observed by intensity of band at 1044 $\mathrm{cm}^{-1}$ (Figure 6a). However in NP-9 spectrum (Figure 6b) observes a higher intensity of the bands at $1044 \mathrm{~cm}^{-1}$ and $919 \mathrm{~cm}^{-1}$ characteristics of menthol highlighting a higher this compound quantity in NP-9 particles.

\subsection{Thermal properties of menthol/PLGA nano/microparticles}

DSC parameters (Tg, Tm and Tc) of PLGA, menthol, PVA and some microparticles are shown in the Table 2.

Glass transition temperature ( $\mathrm{Tg}$ ) of pure PLGA appears around $53^{\circ} \mathrm{C}$ (Table 2) and there was no melting peak or crystallization peak observed in the DSC analysis due to the amorphous nature of this copolymer ${ }^{25,31}$. However the menthol has a melting peak at around $32^{\circ} \mathrm{C}$ and crystallization peak at $18^{\circ} \mathrm{C}$, whereas the poly (vinyl alcohol) has a $\mathrm{Tg}$ around 


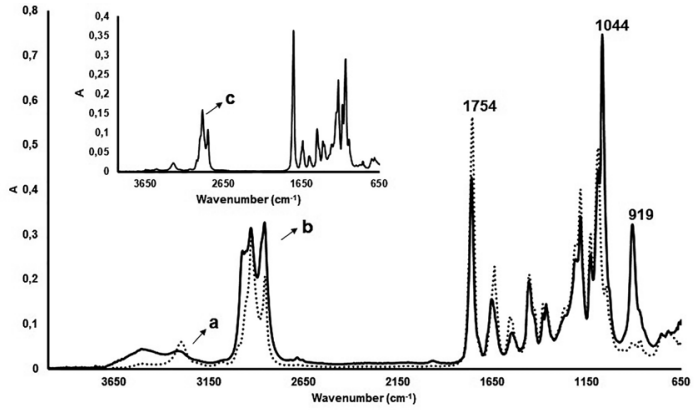

Figure 6. FTIR espectra of the microspheres: (a) NP-6, (b) NP-9 and (c) PLGA particles

Table 2. Some parameters obtained from the DSC analyses of the initial components and nano/microparticles.

\begin{tabular}{lcccc}
\hline Sample & $\operatorname{Tg}\left({ }^{\circ} \mathrm{C}\right)$ & $\mathrm{Tm}\left({ }^{\circ} \mathrm{C}\right)$ & $\mathrm{Tc}\left({ }^{\circ} \mathrm{C}\right)$ & $\begin{array}{c}\Delta \mathrm{Hm} \\
(\mathrm{J} / \mathrm{g})\end{array}$ \\
\hline PLGA & 52.9 & - & - & - \\
PLGA & 48.9 & 177.5 & 126.1 & 2.0 \\
nanoparticles & & 32.5 & 18.3 & 45 \\
Menthol & - & 175.3 & 116.2 & 17.8 \\
PVA & 35.0 & 189.2 & 154.1 & 3.2 \\
NP-3 & 41.5 & - & - & - \\
NP - 5 & 48.0 & 178.5 & 124.6 & 2.2 \\
NP - 6 & 37.2 & 181.4 & 128.6 & 1.9 \\
NP - 9 & 39.8 & & & \\
\hline
\end{tabular}

$35^{\circ} \mathrm{C}$ and $\mathrm{Tm}$ and $\mathrm{Tc}$ around $175^{\circ} \mathrm{C}$ and $116^{\circ} \mathrm{C}$ respectively (Table 2). According to Table 2, the microparticles with a characteristic aroma, such as NP-3, NP-6 and NP-9, showed a Tg between $37^{\circ} \mathrm{C}$ and $41^{\circ} \mathrm{C}$, lower than the the PLGA (pure polymer) Tg and higher than that of PVA. They also showed melting and crystallization points (Table 2) close to those of the PVA. This behavior indicates menthol incorporation in the PLGA matrix, as observed by Owen et al. in the study of ketoprofen-loaded PLGA nanoparticles ${ }^{31}$. Conversely, microparticles without a characteristic aroma, such as NP-5, only presented $\mathrm{Tg}$ at around $48^{\circ} \mathrm{C}$, indicating non-incorporation of menthol. This Tg value is close to the Tg of PLGA (Table 2). PLGA nanoparticles without menthol showed a lower $\operatorname{Tg}\left(48.9^{\circ} \mathrm{C}\right.$, Table 2) than pure PLGA $\left(52.9^{\circ} \mathrm{C}\right)$ due to the preparation process. These results are in line with those found in literature ${ }^{31}$. The values of $177.5^{\circ} \mathrm{C}$ and $126.1^{\circ} \mathrm{C}$ obtained for PLGA nanoparticles (Table 2) refer to the Tm and $T c$, respectively, of the PVA, the external surfactant used in the preparation process of PLGA nanoparticles.

Typical thermogravimetric curves for PLGA/menthol micro/ nanospheres are shown in Figure 7. The thermal degradation behavior of the NP-5 (particles in which no incorporation of menthol was detected) exhibited two degradation steps, from $267^{\circ} \mathrm{C}$ to $389.7^{\circ} \mathrm{C}$ with higher weight loss $(91.5 \%)$ and from $389.7^{\circ} \mathrm{C}$ to $492.7^{\circ} \mathrm{C}$ with lower weight loss $(3.5 \%)$, essentially due to the PLGA polymer decomposition ${ }^{32}$.
However, the NP-3 (particles in which incorporation of menthol was detected) showed four thermal degradation steps: the first two steps between $65^{\circ} \mathrm{C}$ to $155^{\circ} \mathrm{C}$ for menthol and between $155^{\circ} \mathrm{C}$ and $262^{\circ} \mathrm{C}$ for the thermal degradation of PVA and the last two between $262^{\circ} \mathrm{C}$ and $507^{\circ} \mathrm{C}$ due to the thermal decomposition of PLGA nanoparticles (weight loss of $88.2 \%$ ). Similar thermal degradation behavior was observed for the NP-6 and NP-9 (Figure 7), which presented a higher weight loss of $4.0 \%$ and $3.8 \%$ respectively, compared to NP-3 $(2.4 \%)$ in the $56^{\circ} \mathrm{C}$ to $158^{\circ} \mathrm{C}$ range (corresponding to the thermal degradation of menthol), thus indicating that there was a higher incorporation of menthol in NP-6 and NP-9 particles. Weight loss in the step of menthol degradation in the NP-9 was of $3.9 \%$, i.e. approximately $60 \%$ high than NP-3 that was of $2.4 \%$, this result is corroborated by FTIR data.

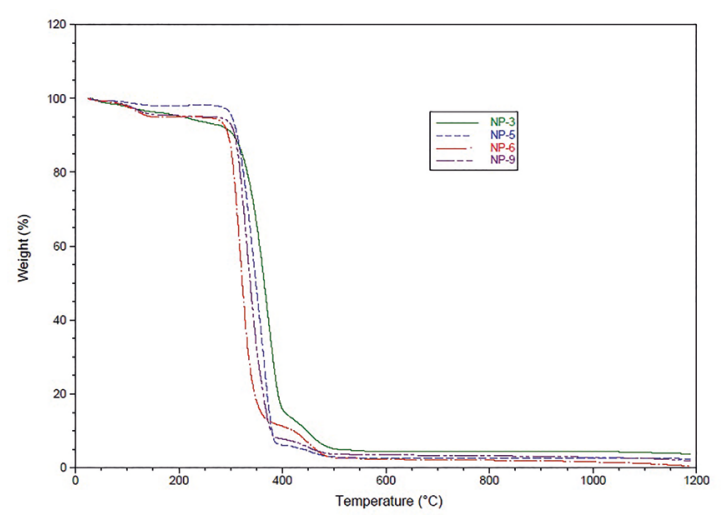

Figure 7. TGA curves of the NP-3, NP-5, NP-6 e NP-9 particles

\subsection{Degradation in artificial saliva}

The menthol/PLGA micro/nanospheres behavior in artificial saliva was evaluated with regard to the weight change of the samples and the $\mathrm{pH}$ of the medium (artificial saliva) by the ninety-day mark. The particles' morphology was also assessed before and after the degradation assay in artificial saliva (Figures 8 and 9).

The highest weight change was approximately $26 \%$ for NP-3 in 7 days and approximately $36 \%$ for NP-5 in 30 days. The greatest weight change was observed up to the 30-day mark for two particles (NP-3 and NP-5). This behavior can be associated with hydrolytic degradation of the PLGA polymer, where the ions present in artificial saliva may contribute to accelerating this degradation process $^{33}$. Additionally, the presence of acidic species, coming from the glycolic and lactic acid segments of the polymer chain, promotes a small decrease in the $\mathrm{pH}$ values up to 30 days (from 6.6 to 6.45 ).

The micrographs of NP-3 and NP-5 (Figures 8 and 9) show the artificial saliva's effect on micro/nanoparticles morphology, where there was a significant change of the spherical or oval particles (Figures $8 \mathrm{a}$ and $9 \mathrm{a}$ ) for wires or ribbons within 30 days (Figures $8 b, 8 c$ and $9 b, 9 c$ ). 

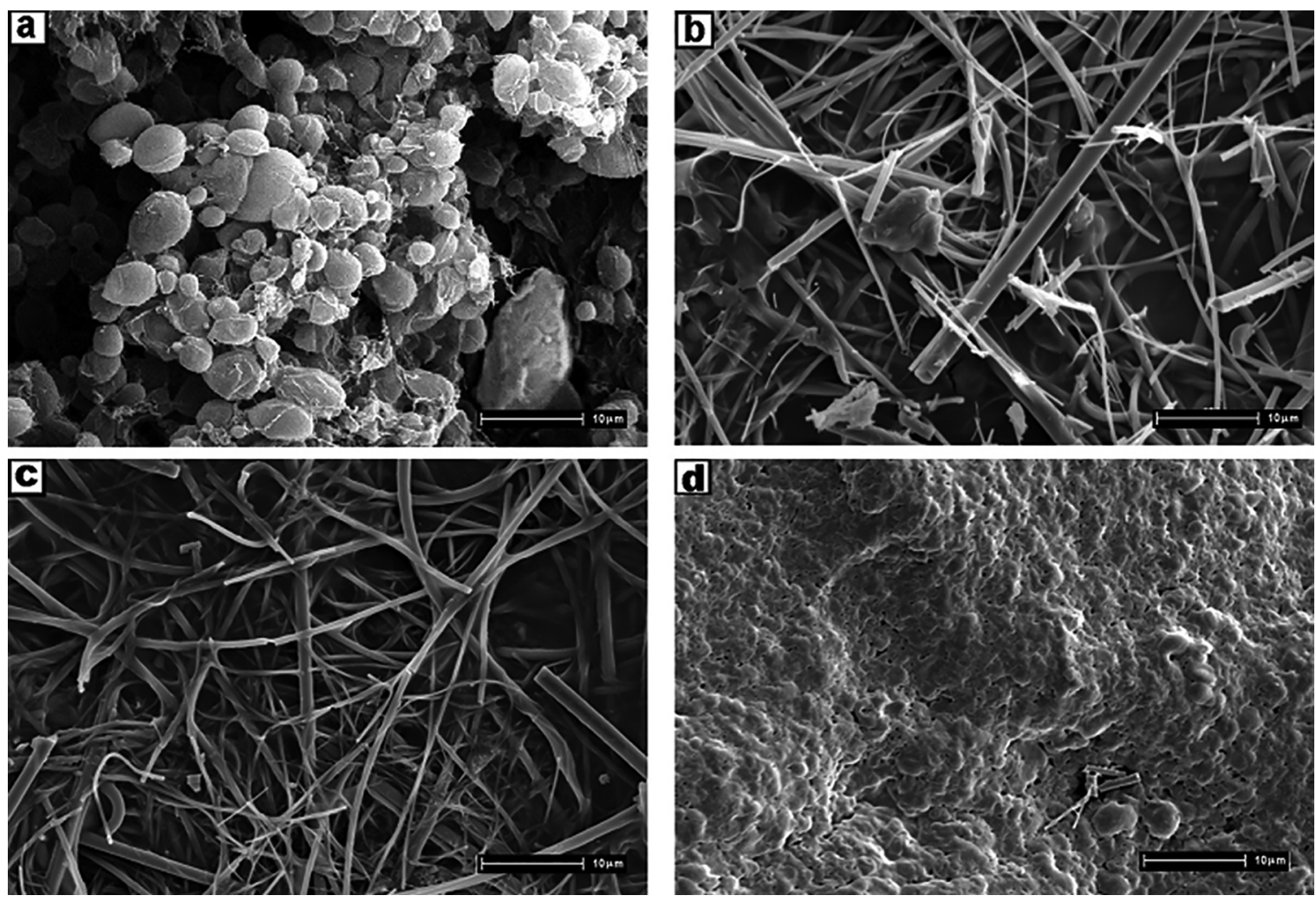

Figure 8. Micrographs of the NP-3 surface after artificial saliva assay: (a) sample at time= 0 days; (b) at 7 days; (c) at 30 days and (d) 90 days
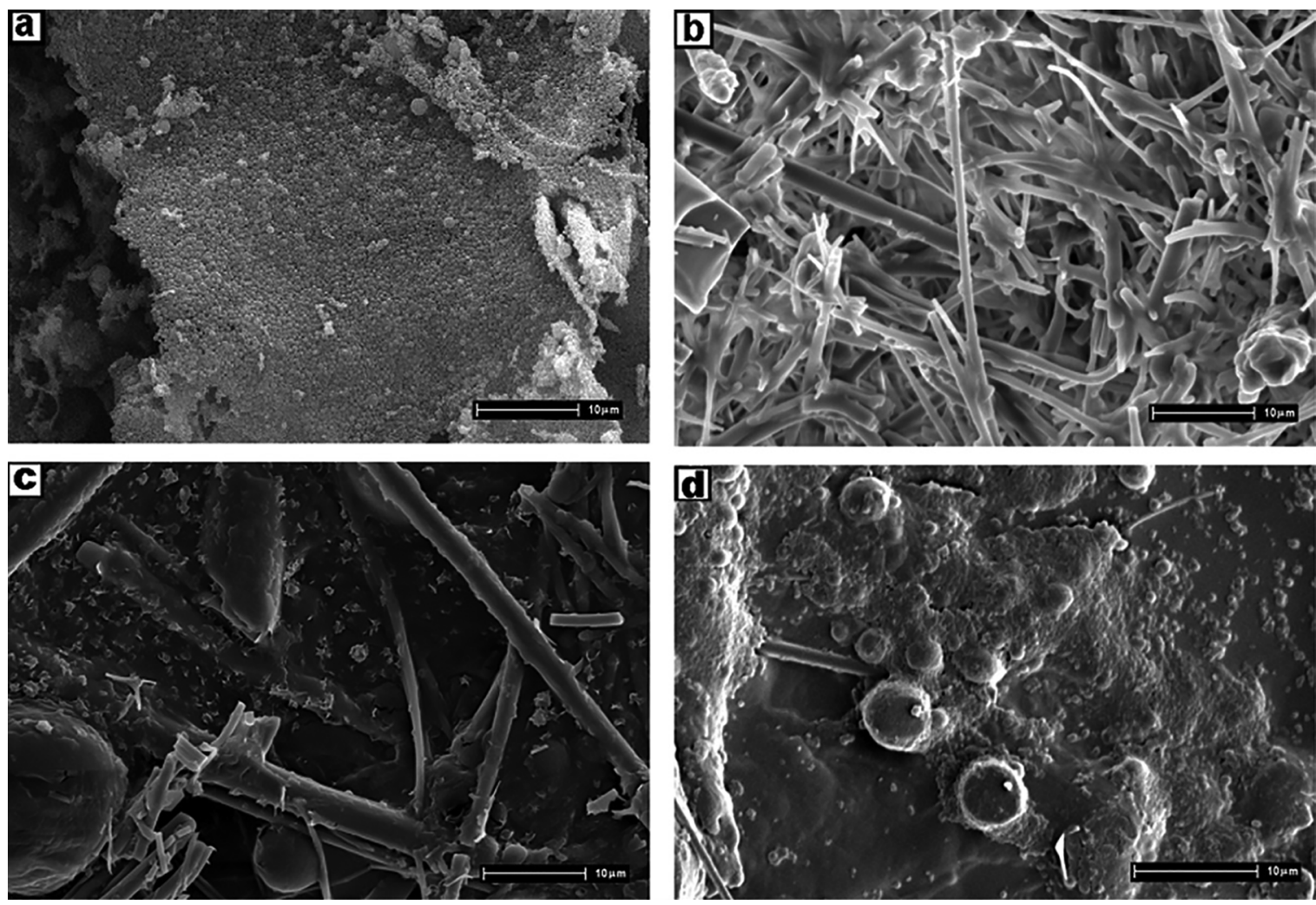

Figure 9. Micrographs of the NP-5 surface after artificial saliva assay: (a) sample at time $=0$ days; (b) at 7 days; (c) at 30 days and (d) 90 days 
However, in longer periods of time (60 and 90 days), the wires or ribbons were observed to disappear and irregular and dense surfaces formed on both particles NP-3 (Figure 8d) and NP-5 (Figure 9d). The literature indicates that this behavior can be associated to the mineralization process since the degradation in artificial saliva was carried out in media with high ions content ${ }^{34}$.

Additionally, menthol appears to have an additive effect on the morphology, since in the NP-3 (particles with menthol) wires or ribbons are formed in greater quantities while the NP-5 present some spheres (Figure 9c) after being in the saliva medium for a long time. In a study where menthol was encapsulated in starch, it could be seen that full aroma release was achieved after 4 hours of hydrolysis in artificial saliva, the time period when the particles are partially degraded and starch hydrolysis is significantly initiated ${ }^{35}$. In another degradation study of a natural thermoplastic polymer in simulated saliva fluid, the surface and bulk degradation were seen to take place at the same time, completely changing the polymer morphology ${ }^{36}$.

TGA analyses were performed for NP-3 and NP-5 samples after degradation in artificial saliva (TGA curves not shown). After 7 days there was no degradation event observed between $65^{\circ} \mathrm{C}$ to $155^{\circ} \mathrm{C}$, relating to the menthol degradation in the NP-3 particles, while with the NP-5 particles, there were no signals present under the same conditions.

\section{Conclusion}

Using the multiple emulsion/solvent evaporation technique made it possible to prepare the micro-nanoscale for a controlled release delivery system of aroma. The menthol/ PLGA spheres in micro/nanometric size (13 $\mu \mathrm{m}$ to $217 \mathrm{~nm}$ ) were obtained with high mixing speed $(24,000 \mathrm{rpm})$ for the emulsion and a long solvent evaporation time (12h) and lyophilization time (24h). The presence or absence of aroma in the micro/nanospheres was evaluated using the FTIR, DSC and TGA techniques. Moreover, a preliminary assessment made by FTIR and TGA showed that the increase in the menthol/PLGA ratio (weight ratio= 1:2.5, NP-9) resulted in approximately $60 \%$ increase in incorporated menthol when compared with NP-6 (weight ratio=1:5). It should be highlighted that menthol was released from the PLGA under simulated saliva conditions. This result indicates that the PLGA polymer can serve as an efficient matrix for the control release of aroma in the oral cavity.

\section{Acknowledgements}

The authors would like to thank Hewlett-Packard Brasil Ltda for the scholarship (JPH), FINEP and PRONEX/ FAPERGS for financial support and LabCEMM/PUCRS. $\mathrm{SE}$ and RL acknowledge CNPq for the DT grant.

\section{References}

1. Crucho CIC, Barros MT. Formulation of functionalized PLGA polymeric nanoparticles for targeted drug delivery. Polymer. 2015;68:41-46.

2. Sui X, Wei W, Yang L, Zu Y, Zhao C, Zhang L, et al. Preparation, characterization and in vivo assessment of the bioavailability of glycyrrhizin acid microparticles by supercritical antisolvent process. International Journal of Pharmaceutics. 2012;423(2):471-479.

3. Durán N, Mattoso LHC, Morais PC. Nanotecnologia: Introdução, Preparação e Caracterização de Nanomateriais e Exemplos de Aplicação. São Paulo: Artliber; 2006.

4. Suave J, Dall'Agnol EC, Pezzin APT, Silva DAK, Meier MM, Soldi V. Microencapsulação: Inovação em diferentes áreas. Revista Saúde e Ambiente/Health and Environment Journal. 2006;7(2):12-20.

5. Tran VT, Benoit JP, Venier-Julienne MC. Why and how to prepare biodegradable, monodispersed, polymeric microparticles in the field of pharmacy? International Journal of Pharmaceutics. 2011;407(1-2):1-11.

6. Melo NFS, Grillo R, Rosa HA, Fraceto LF, Dias Filho NL, de Paula E, et al. Desenvolvimento e caracterização de nanocápsulas de poli (L-lactídeo) contendo benzocaína. Química Nova. 2010;33(1):65-69.

7. Beck RCR, Lionzo MIZ, Costa TMH, Benvenutti EV, Ré MI, Gallas MR, et al. Surface morphology of spray-dried nanoparticles-coated microparticles designed as an oral drug delivery system. Brazilian Journal of Chemical Engineering. 2008;25(2):389-398.

8. Soares AQ, Oliveira LF, Rabelo D, Souza AR. Polímeros Biodegradáveis: Novas perspectivas para as ciências farmacêuticas. Revista Eletrônica de Farmácia. 2005;2(2):202-205.

9. Holland SJ, Tighe BJ, Gould PL. Polymers for biodegradable medical devices. 1. The potential of polyesters as controlled macromolecular release systems. Journal of Controlled Release. 1986;4(3):155-180

10. De Ávila SC, Holz JP, Carone CLP, Morisso FD, Ligabue RA, Pighinelli L. Microcapsules PCL with Essential Oil Citronella. Advances in Tissue Engineering and Regenerative Medicine. 2017;2(2):00024.

11. Uskokovic D, Stevanovic M. Poly(lactide-co-glycolide)-based Micro and Nanoparticles for the Controlled Drug Delivery of Vitamins. Current Nanoscience. 2009;5(1):14p.

12. Kamatou GPP, Vermaak I, Viljoen AM, Lawrence BM. Menthol: A simple monoterpene with remarkable biological properties. Phytochemistry. 2013;96:15-25.

13. Turcheniuk V, Raks V, Issa R, Cooper IR, Cragg PJ, Jijie R, et al. Antimicrobial activity of menthol modified nanodiamond particles. Diamond and Related Materials. 2015;57:2-8

14. Liu Z, Shen C, Tao Y, Wang S, Wei Z, Cao Y, et al. Chemopreventive efficacy of menthol on carcinogen-induced cutaneous carcinoma through inhibition of inflammation and oxidative stress in mice. Food and Chemical Toxicology. 2015;82:12-18. 
15. Suankaew N, Matsumura Y, Saramala I, Ruktanonchai UR, Soottitantawat A, Charinpanitkul T. L-Menthol crystal micronized by rapid expansion of supercritical carbon dioxide. Journal of Industrial and Engineering Chemical. 2012;18(3):904-908.

16. Martins IM, Barreiro MF, Coelho M, Rodrigues AE. Microencapsulation of essential oils with biodegradable polymeric carriers for cosmetic applications. Chemical Engineering Journal. 2014;245:191-200.

17. Gonnet M, Lethuaut L, Bury F. New trends in encapsulation of liposoluble vitamins. Journal of Controlled Release. 2010;146(3):276-290.

18. Fornaguera C, Dols-Perez A, Calderó G, García-Celma MG, Camarasa J, Solans C. PLGA nanoparticles prepared by nanoemulsion templating using low-energy methods as efficient nanocarriers for drug delivery across the blood-brain barrier. Journal of Controlled Release. 2015;211:134-143.

19. Lee YS, Johnson PJ, Robbins PT, Bridson RH. Production of nanoparticles-in-microparticles by a double emulsion method: A comprehensive study. European Journal of Pharmaceutics Biopharmaceutics. 2013;83(2):168-173.

20. Lima KM, Silva CL, Rodrigues Júnior JM. Microesferas biodegradáveis. Biotecnologia: Ciência \& Desenvolvimento. 2000;2(12):10-13.

21. Jiang Y, Wang F, Xu H, Liu H, Meng Q, Liu W. Development of andrographolide loaded PLGA microspheres: optimization, characterization and in vitro-in vivo correlation. International Journal of Pharmaceutics. 2014;475(1-2):475-484.

22. Schaffazick SR, Guterres SS, Freitas LL, Pohlmann AR. Caracterização e estabilidade físico-química de sistemas poliméricos nanoparticulados para administração de fármacos. Química Nova. 2003;26(5):726-737.

23. Ashjari M, Khoee S, Mahdavian AR. A multiple emulsion method for loading 5-fluorouracil into a magnetite-loaded nanocapsule: a physicochemical investigation. Polymer International. 2012;61(5):850-859.

24. Tavandashti NP, Ghorbani M, Shojaei A. Morphology transition control of polyaniline from nanotubes to nanospheres in a soft template method. Polymer International. 2015;64(1):88-95.

25. 25. Motta AC, Duek EAR. Síntese, caracterização e degradação "in vitro" do poli (L-ácido láctico-co-ácido glicólico). Matéria (Rio de Janeiro). 2006;11(3):340-350.
26. Silverstain RM, Bassler GC, Morril TC. Identificação Espectrométrica de Compostos Orgânicos. Rio de Janeiro: Guanabara Koogan; 1994.

27. Feczkó T, Tóth J, Dósa G, Gyenis J. Influence of process conditions on the mean size of PLGA nanoparticles. Chemical Engineering and Processing. 2011;50(8):846-853.

28. Rao JP, Geckeler KE. Polymer nanoparticles: Preparation techniques and size-control parameters. Progress in Polymer Science. 2011;36(7):887-913.

29. Abdelwahed W, Degobert G, Fessi H. A pilot study of freeze drying of poly(epsilon-caprolactone) nanocapsules stabilized by poly(vinyl alcohol): Formulation and process optimization. International Journal of Pharmaceutics. 2006;309(1-2):178188.

30. Kasper JC, Friess W. The freezing step in lyophilization: Physicochemical fundamentals, freezing methods and consequences on process performance and quality attributes of biopharmaceuticals. European Journal of Pharmaceutics and Biopharmaceutics. 2011;78(2):248-263.

31. Corrigan OI, Li X. Quantifying drug release from PLGA nanoparticulates. European Journal of Pharmaceutical Sciences. 2009;37(3-4):477-485.

32. Mainardes RM, Gremião MPD, Evangelista RC. Thermoanalytical study of praziquantel-loaded PLGA nanoparticles. Revista Brasileira de Ciências Farmacêuticas. 2006;42(4):523-530.

33. Pagès-Hélary S, Andriot I, Guichard E, Canon F. Retention effect of human saliva on aroma release and respective contribution of salivary mucin and a-amylase. Food Research International. 2014;64:424-431.

34. Bleek K, Taubert A. New developments in polymer-controlled, bioinspired calcium phosphate mineralization from aqueous solution. Acta Biomaterialia. 2013;9(5):6283-6321.

35. Ades H, Kesselman E, Ungar Y, Shimoni E. Complexation with starch for encapsulation and controlled release of menthone and menthol. LWT - Food Science and Technology. 2012;45(2):277288 .

36. Shi R, Ding T, Liu Q, Han Y, Zhang L, Chen D, et al. In vitro degradation and swelling behaviour of rubbery thermoplastic starch in simulated body and simulated saliva fluid and effects of the degradation products on cells. Polymer Degradradation and Stability. 2006;91(12):3289-3300. 